Artículos

\title{
LAS OBEDIENCIAS MASÓNICAS DEL RITO DE YORK COMO CENTROS DE ACCIÓN POLÍTICA, MÉXICO, 1825-1830
}

\author{
María Eugenia Vázquez Semadeni
}

Resumen: La masonería mexicana de las primeras décadas del siglo XIX estuvo estrechamente ligada con la actividad política del naciente país. Las identidades políticas de los grupos que contendían por el poder fueron construidas —en el debate público - a partir de sus proyectos de nación, de su concepción del sistema político y de la forma de gobierno que preferían, pero también se delinearon a partir de sus pertenencias masónicas: escoceses y yorkinos. Sobre las obediencias que trabajaban en el rito escocés existen muy pocos datos, pero las del rito de York sí dejaron memoria de la forma en que sus miembros utilizaron la estructura organizativa de la masonería para obtener apoyo político, para orientar los resultados electorales, para legitimar su acceso a los cargos públicos, para exigir acciones gubernamentales. El objetivo de este trabajo es mostrar cómo las estructuras jerárquicas de la masonería, sus canales de comunicación y las lealtades que generaba fueron aprovechadas por los miembros de la organización yorkina para convertirla en un centro de acción política. Y cómo el grupo yorkino principal, ubicado en la capital del país y agrupado en torno a la Gran Logia Nacional Mexicana, aprovechó también la estructura institucional del nuevo sistema político para obtener apoyo mediante la filiación yorkina.

Palabras clave: Masonería, yorkinos, escoceses, centro de acción política, cultura política, procesos electorales.

María Eugenia Vázquez Semadeni, doctora en Historia, por El Colegio de Michoacán, adscrita al Instituto de Investigaciones Históricas, Universidad Nacional Autónoma de México, temas de especialización: Masonería, debate público y cultura política del México decimonónico; Formación de grupos políticos en México, en la década de 1830. Correo electrónico: maruvas@prodigy.net.mx; maryuvas@gmail.com.
Abstract: On the first few decades of the 19th Century, Mexican masonry was very close to the political activity of the new-born country. The public identities of the political groups in competition for political power were constructed-through the public papers- on the basis of their projects for the nation, their conception of the political system, and their preferred form of government. But those identities were also defined around their members`'Masonic relations. Those groups were known as escoceses and yorkinos.

Very limited information exists about the Scottish rite in Mexico during that period, but the York rite did leave records about the way their members used the Masonic structure to obtain political support, to orient election results, to legitimize their access to public offices, and to demand government actions. The aim of this paper is to show how Masonry's hierarchical structures, its communication channels, and the loyalties it created were used by yokino masons to turn the York rite into a center of political activity, and how the main yorkinos, operating in Mexico City, used the Mexican institutional structure to get political support through their yorkino affiliation.

Key words: Masonry, yorkinos, escoceses, center of political activity, political culture, elections.

Enviado a dictamen: 25 de julio de 2009

Aprobación: 28 de agosto de 2009

Revisiones: 1 


\section{Introducción}

L a masonería mexicana de las primeras décadas del siglo XIX estuvo estrechamente ligada con la actividad política del naciente país. ${ }^{1}$ Por una parte, porque los principales o más destacados masones de estos años fueron también algunos de los más relevantes actores políticos; por otra, las imágenes públicas de los grupos que contendían por el poder político se construyeron, entre otras cosas, en torno a las filiaciones masónicas de sus miembros. Además, los masones, en especial quienes establecieron y difundieron las obediencias del rito de York en México, ${ }^{2}$ utilizaron la estructura organizativa de la masonería para obtener apoyo político, para orientar los resultados electorales o para legitimar su acceso al poder.

El objetivo de este trabajo es mostrar cómo los cuerpos masónicos, algunas de las prácticas internas de la masonería, sus canales de comunicación y las lealtades que generaba fueron aprovechadas por los yorkinos para establecer un centro de acción política, es decir, un espacio donde se elaboraban acuerdos y desde el cual se ejecutaban acciones para alcanzar, conservar y ejercer el poder político (Flores, 2005: 126). Como se verá, esto en parte fue posible gracias a la estructura institucional derivada del establecimiento del sistema republicano, representativo y federal; pero también a que los yorkinos elaboraron un discurso acerca del sistema político, de sí mismos y de sus contrincantes, que durante un tiempo proporcionó notable legitimidad a sus acciones políticas.

Realizar un estudio de este tipo reviste gran dificultad, porque en México son muy escasas las fuentes masónicas para la primera mitad del siglo XIX. Sin embargo, he podido localizar algunos documentos que, aunados a las fuentes hemerográficas y bibliográficas, proporcionan información suficiente para sustentar la investigación. Me refiero a una serie de cartas, planchas, ${ }^{3}$ circulares, certificados, nombramientos y cédulas elaboradas por masones, la mayoría yorkinos, así como el juicio masónico seguido en 1827 a un miembro de la logia "Apoteosis de Hidalgo", que trabajaba en el rito York en la ciudad de Chihuahua, y otro, en 1830 en el tribunal eclesiástico al presbítero Antonio Arroyo por pertenecer a la logia de Zacatlán, también del rito de York. Algunos de estos documentos se encontraban dispersos en colecciones particulares y fueron subastados en fechas recientes por la casa Louis C. Morton; otros se localizan en diversos repositorios mexicanos, como el Archivo General de la Nación, la colección Lafragua de la Biblioteca Nacional, el Archivo de la Suprema Corte de Justicia de la Nación y el Archivo Histórico del Arzobispado de México.

Cabe mencionar que la consulta de la hemerografía y la bibliografía implica un profundo trabajo de crítica de fuentes. Durante el periodo en estudio, la masonería fue una asociación en torno a la cual se crearon múltiples rumores, porque privaba una imagen pública muy negativa sobre ella, heredada de la literatura antimasónica europea. Además, la actuación política secreta generaba temor y se contraponía a la nueva concepción del orden político que exigía el sometimiento de las acciones de las autoridades a la opinión pública (Vázquez, 2008). Por tales razones, en muchos casos de los papeles públicos, o en las obras de autores decimonónicos que estuvieron involucrados en los acontecimientos que narran, se magnificaba o minimizaba la actuación pública de la masonería, se señalaba como masones a personas que no lo eran, se les imputaban acciones que no habían cometido, incluso parece probable que algunos de los documentos que publicaban fueran apócrifos. Es preciso entonces, en este tipo de trabajos, distinguir el rumor de las referencias documentales. Para ello, se confrontó la información contenida en los documentos arriba mencionados con la que aparecía en los papeles públicos y la que ofrecen los principales autores de la época, a fin de deducir en un considerable grado de certidumbre cuáles datos son confiables y cuáles no. ${ }^{4}$ 


\section{La primera masonería en México}

La masonería organizada parece haberse establecido en México durante la guerra civil que culminó en la independencia, aunque la fecha exacta se desconoce. José María Luis Mora afirmó que fue en 1813, mientras que Lucas Alamán señaló que fue en 1817 o 1818. Otro, José María Tornel apuntó que fue en 1820. De acuerdo con Alamán y Mora, las primeras logias que se instauraron trabajaban bajo el rito escocés y estaban integradas por españoles, miembros de las tropas expedicionarias, y algunos religiosos franciscanos, dirigidas por el oidor español Felipe Martínez de Aragón y Fausto de Elhuyar, aunque también se incorporaron a ellas algunos americanos destacados, como José María Fagoaga, Ignacio García Illueca y Tomás Murphy (Alamán, 1986: 43; Mora, 1963: 7-8; Tornel, 1985: 28).

Las afirmaciones de estos historiadores coinciden con las de José María Chavero (1829: 26 de agosto), quien señaló que desde mucho antes de la independencia existía una logia escocesa titulada "Arquitectura moral", dirigida por el oidor Martínez, y ubicada en la calle de Santa Teresa la Antigua, casa número 2. ${ }^{5}$ Aseguró que dicho taller estaba compuesto de numerosos "gachupines", enemigos de la independencia, al cual se incorporaron escasos americanos que también se inclinaban por mantener la unión con la monarquía; entre ellos el escritor Francisco Ibar, quien más tarde sería uno de los más acérrimos enemigos de los yorkinos.

Estas narraciones decimonónicas ubican a las primeras logias en la ciudad de México; sin embargo, también se tienen noticias de la temprana existencia de, al menos, una logia en Veracruz. En 1816 se siguieron dos causas en la Inquisición por francmasonería. En la primera de ellas, Francisco Vicente Pérez Durán señaló que en 1814 había conocido y tratado a Gonzalo de Ulloa - Teniente de Fragata y Comandante del cuerpo de patriotas de la plaza de Veracruz-, quien le confesó ser francmasón y le comentó sobre la existencia de una logia en aquella ciudad. En la segunda, seguida en Zacatecas, Juan
Antonio Zarandona expresó que Juan José Martínez — mercader viandante originario de Vigo - aseguraba que en Veracruz había muchos masones, y que en Zacatecas también existían algunos, entre ellos el propio Intendente José de Gayangos, quien había asistido a la logia en Veracruz (AGN, Inq.). Desafortunadamente estas causas no proporcionan información sobre el rito en el que trabajaba esa logia veracruzana; ni permiten saber si era la misma o si había más de una, pero al menos muestran la temprana presencia de masonería organizada en aquella zona.

En la década de 1810-1820 también hubo actividad masónica organizada en la Península de Yucatán. La masonería arribó a Campeche alrededor de 1817, por la llegada de militares emigrados de la metrópoli y por el naufragio de la fragata Ifigenia, entre cuyos pasajeros venían varios masones. Estos masones trabajaban en el rito escocés, que difundieron en esa provincia, y a cuyas logias se incorporó la alta jerarquía militar y los ricos comerciantes de la zona. Por esas fechas, en Mérida se fundó una logia del rito de York, llamada "La Aurora", al parecer establecida por el español José de Obando y Adorno, a la que se incorporó también un grupo importante de militares y eclesiásticos. Unos años después esta logia se cambió al rito de Escocia (Campos, 2003).

En 1822 el Gran Consistorio ${ }^{6}$ del Rito Escocés de aquella zona buscó incorporar a su jurisdicción a las logias establecidas en distintas ciudades yucatecas, para lo cual nombró inspector al Capitán General de Yucatán, Melchor Álvarez, a fin de que éste otorgara el grado de Rosa Cruz a doce miembros propuestos por las logias locales y formara un Capítulo provincial ${ }^{7}$ (Campos, 2003: 90-91). Este cuerpo masónico tuvo una importante relación con el Gran Consistorio de La Habana. De hecho, es muy probable que este último haya colaborado para la instalación del Gran Consistorio de Yucatán, mismo que inicialmente debe haber estado bajo su jurisdicción, pues en 1822 se publicó un discurso del Gran Consistorio de Yucatán, que se despedía del de La Habana, porque se uniría al Gran Consejo de Vera- 
cruz (Gran Consistorio, 1822). ${ }^{8}$ En 1818 se había fundado en aquella ciudad cubana un Gran Consistorio del grado 32 del Rito Escocés Antiguo y Aceptado (Castellano, 1996: 49), de modo que posiblemente a ese cuerpo estaba dirigido el discurso de despedida del de Yucatán.

Ese documento permite constatar que para 1822 los grados superiores del rito escocés ya estaban organizados tanto en la Península de Yucatán como en Veracruz, lo cual hace suponer que ya tenía tiempo funcionando.

Otro aspecto por el cual la masonería cubana fue importante para la primera masonería en México, fue que al menos dos de los masones más destacados y políticamente activos en México se iniciaron en La Habana: José María Alpuche, en 1804 (Registro, 1830: 10 de marzo), y Manuel Gómez Pedraza, en 1821 (Gómez, 1821: 29). La relación de mexicanos con la masonería en Cuba y en España —donde se iniciaron al menos José María Fagoaga, Servando Teresa de Mier y Miguel Santa María (AGN, Ind.) - ${ }^{9}$ fue sin duda otro medio para que esta asociación se diera a conocer en este territorio, amén de que debe haber contribuido a la expansión de logias del rito escocés en la capital, pues, según la historiografía, Fagoaga y Santa María se incorporaron a ellas cuando regresaron a México.

Poco se sabe acerca de la actividad política de los primeros masones en México..$^{10}$ Los historiadores decimonónicos tienden a sostener que los escoceses fraguaron el Plan de Casa Mata, a partir del cual se precipitó la caída del imperio de Agustín de Iturbide, que estableció en México tras la consumación de la independencia. Hasta ahora no se han encontrado elementos suficientes para afirmar que todo ese plan haya sido formulado por la masonería (Ávila, 2004a: 257-258), pero sí he podido comprobar que la logia "Aurora Yucateca" se manifestó en contra de las que llamaba "medidas despóticas" de Iturbide, como la disolución del congreso, y a favor de las disposiciones de la Junta de Becal, la cual se adhirió al Plan de Casa Mata ([“Aurora”], 1823; Zuleta, 2003: 166)."
Este es uno de los primeros casos en los que pueden observarse cómo los miembros de la masonería, actuando en su calidad de masones y expresándose a nombre de su organización, ejecutaron acciones políticas. La logia "Aurora Yucateca" ofreció al Capitán General Melchor Álvarez "el mallete, la pluma y la espada” para la defensa de su persona y de las libertades que consideraban violentadas por Iturbide ([“Aurora”], 1823). Sin embargo, como se verá, este tipo de funcionamiento fue mucho más claro en el caso de las obediencias del rito de York, o por lo menos, se conservan más fuentes para documentarlo.

\section{Fundación y expansión del rito de York}

Tras la caída de Iturbide en 1823, los grupos políticos de las provincias exigieron el establecimiento de una república federal, que respetara la autonomía de las regiones. En octubre del siguiente año, fue promulgada la Constitución Federal y se eligió presidente a Guadalupe Victoria. Una parte de los masones escoceses se había inclinado, primero, por mantener la unión con la monarquía hispánica, después, por la monarquía constitucional y finalmente, algunos de ellos preferían la república central y habían estado en contra de la elección de Victoria, lo cual provocó que el nuevo gobierno se sintiera temeroso de su influjo (Alamán, 1986: 89, 410, 474). Contrarrestarlo debe haber sido una de las razones que llevaron a varios actores políticos mexicanos a establecer logias del rito de York en el país, con el fin de oponerse a sus contrincantes con sus mismos medios y conseguir un espacio de organización para la consolidación del proyecto republicano federal. Para hacerlo contaron con el impulso del ministro plenipotenciario norteamericano Joel R. Poinsett, quien era un prominente miembro de la masonería estadounidense y deseaba instruir a los políticos mexicanos en el funcionamiento de las instituciones federalistas, para lo cual la masonería yorkina le parecía un medio idóneo (Ávila, 2004c: 52-53; Rich, 1997). 
La mayoría de los autores decimonónicos coinciden en señalar que la organización de las obediencias yorkinas en México se inició alrededor de septiembre de 1825 y que entre sus principales promotores se encontraban algunos emigrados del rito escocés como Lorenzo de Zavala, José María Alpuche, José María Tornel y Miguel Ramos Arizpe (Alamán, 1986: 474; Zavala, 1831-32:257-258; Tornel, 1985:46).

La carta patente para la Gran Logia Nacional Mexicana fue obtenida, en 1826, de la Gran Logia de Nueva York, gracias a la intermediación de Poinsett. ${ }^{12}$ Con base en las solicitudes de títulos presentadas a dicha Gran Logia, Costeloe indica que algunos de los personajes que se incorporaron posteriormente al rito fueron Félix María Aburto, Juan Nepomuceno Pérez, José N. Telles, José María Tornel, Alexander Yhary, Antonio J. Valdés, Albino Pérez, Vicente Guerrero, José Serrano, Pedro María Anaya, Juan Unzueta, Guillermo Gardette, José de Aldana y José Manuel Palomino (Costeloe, 1996: 50). A esta lista pueden añadirse Agustín Viesca, Vicente Filisola, Luis Cortázar, Joaquín Parrés, Juan José Codallos, Zenón Fernández, Anastasio Bustamante, José Ignacio Basadre, [José María] Chavero, Mariano Arista, Juan Andrade, Manuel Reyes Veramendi, José María Arechaga, [i?] Inclán y [Eugenio] Tolsá, quienes son mencionados por el historiador de la masonería José María Mateos (2003: 16) como algunos de sus primeros integrantes. He podido ubicar también como masones yorkinos en 1826 a José Manuel Herrera, al emigrado cubano José Teurbe Tolón y a Isidro Gondra (Herrera, 1826).

Los cuerpos masónicos que trabajaban en el rito de York se extendieron rápidamente. Gracias a las cartas de José María Tornel (1826b) y Mariano Arista (1826), es posible constatar que para 1826 se habían instalado ya por lo menos 18 logias simbólicas, ${ }^{13}$ un taller ambulante $^{14}$ en el regimiento número 2, la Gran Logia Nacional Mexicana, ubicada en la ciudad de México, y un Capítulo de Reales Arcos, ${ }^{15}$ titulado "La Libertad". Por todo ello, Lorenzo de Zavala se congratulaba de la rápida expansión que estaba teniendo la "masonería Republicana de York" (Zavala, 1826).
Durante 1826 y 1827 los dirigentes de la Gran Logia Nacional Mexicana se dedicaron a tratar de extender por el país el influjo de su organización. Para ello aprovecharon la estructura institucional del nuevo sistema político y las relaciones que ésta les permitió entablar. Por ejemplo, debido a que el sistema era representativo y federal, en la Ciudad de México se instauró un congreso nacional al que acudieron legisladores de todos los estados de la federación. Los principales yorkinos que se encontraban en la capital, muchos de los cuales también ocupaban importantes cargos públicos, pudieron conocer a los actores políticos locales que llegaban a la ciudad y vincularse con aquellos que tenían proyectos políticos semejantes al suyo. Algunos de esos legisladores estatales se iniciaron en la masonería del rito de York, y cuando regresaron a sus ciudades de origen llevaban la comisión de establecer logias en ellas. Así sucedió con Santiago Abreu, diputado por Nuevo México, a quien el Gran Maestro de la Gran Logia Nacional Mexicana, Vicente Guerrero, otorgó poderes para establecer una logia simbólica en Chihuahua (Guerrero, 1827). ${ }^{16}$ De forma semejante, cuando el gobierno nacional nombró a Anastasio Bustamante como Comandante General de las Provincias Internas de Oriente, éste llevaba la encomienda de dar a conocer la masonería yorkina en aquella parte del país (Bustamante, 1826; Madero, 2003: 315-321). Además se establecieron logias ambulantes en varios regimientos del ejército, que también contribuyeron a la expansión de los cuerpos yorkinos fuera de la zona central de la República.

Para 1828 la estructura masónica del rito de York se había extendido en México de forma notable. De acuerdo con el catálogo elaborado por Agustín Viesca, entonces Gran Secretario de la Gran Logia Nacional Mexicana, en ese año ésta tenía bajo su jurisdicción 102 logias simbólicas, aunque no me parece posible comprobar este número. La mayor concentración de logias se daba en el Estado de México, el Distrito Federal, Veracruz y Puebla; en el Norte y en el Sur del país eran un poco más escasas, sin embargo, había al menos una 
logia en todos los estados que componían la Federación. El número de talleres ambulantes en los regimientos del ejército también había aumentado significativamente, pues había llegado a trece (Ibar, 1830). Y en el estado de Puebla se había establecido otra Gran Logia, aunque se desconoce cuántas logias tenía bajo su jurisdicción (Gran Logia, 1828). ${ }^{17}$

\section{El discurso yorkino y la formación de las imágenes públicas}

Prácticamente desde que las obediencias del rito de York se establecieron en México, varios publicistas que se habían iniciado en él, o que al menos eran partidarios de su proyecto político, se dedicaron a construir la imagen pública del grupo yorkino y del que consideraban su contrincante: el escocés. Con ello, las divisiones que se habían creado en la clase política mexicana desde la independencia, que primero se definieron en el debate público con los términos españoles de liberales y serviles, y más tarde con los de iturbidistas-federalistas y borbonistas-centralistas, se trasladaron a las categorías masónicas de escoceses y yorkinos. En realidad, esas divisiones en la clase política no eran tan tajantes como las presentó el debate público. Los yorkinos radicalizaron las imágenes públicas que se habían creado en los impresos, y las retomaron para formular su discurso político (Vázquez, 2008).

En torno a esas imágenes públicas, los escritores del periodo discutieron sobre la forma en que entendían el nuevo sistema político, la manera en que debían funcionar las instituciones y las prácticas que lo sustentaban, y a definir sus conceptos fundamentales como la soberanía, la representación, la legitimidad, entre otros. La formulación de las imágenes públicas tuvo entonces gran importancia, porque los grupos que se disputaban el poder quedaron identificados con una serie de principios que legitimaban o deslegitimaban sus acciones políticas.

Debido a que entre los masones escoceses había numerosos españoles, y a que muchos se habían mostrado a favor de la monarquía constitucional e incluso a favor de seguir unidos a la metrópoli (Alamán, 1986: 89), fue fácil para los publicistas yorkinos acusar a los escoceses de enemigos de la independencia y de la república. Además, al grupo escocés se incorporaron también algunos personajes que eran considerados partidarios de la república central, como Nicolás Bravo, ${ }^{18}$ con lo que también se les catalogó como enemigos de la federación. Por último, en las filas escocesas había personajes como José María Fagoaga, miembros de los sectores social, económica y políticamente privilegiados de la capital; y en ese sentido el discurso yorkino los calificó de "aristócratas", que preferían un sistema central para controlar el país despóticamente desde el centro. Con estos planteamientos, el discurso yorkino unificó en un solo grupo a todos sus contrincantes políticos, de tal modo que, mediante sus vínculos masónicos, en los escoceses quedaron agrupados todos los supuestos "enemigos de la patria" y de los principios que sustentaban el nuevo orden político.

Al mismo tiempo, los yorkinos se construyeron una imagen pública propia en la que se identificaron con la defensa de una serie de principios, proyectos y valores que, según sostenían, eran los que defendía la mayoría de la nación: la independencia, la libertad, el sistema americano, el federalismo, la república, la igualdad y una amplia participación política. Con ello, lograron presentarse como los voceros de la voluntad general, como los protectores de los intereses nacionales y del sistema político elegido por los mexicanos. ${ }^{19}$

Esta estrategia fue sumamente hábil, pues gracias a ella lograron hacer aparecer a los escoceses como una mera facción, que por proteger sus miras particulares estaba dispuesta a renunciar a los logros de los patriotas, nombre que los yorkinos adoptaron y con el que se presentaban en los papeles públicos. Su discurso fue capaz de inhibir políticamente a sus contrincantes durante algunos años, pues cada propuesta o acto de algún personaje catalogado como escocés era inmediatamente calificado de borbónico, tendiente a 
la reconquista o al menos de desestabilizador. ${ }^{20}$ Ello limitó el apoyo que recibieron los proyectos de los llamados escoceses e incluso, durante un tiempo, sus triunfos electorales.

Por todo lo anterior, es posible sostener que una parte fundamental de la actuación política de los yorkinos fue el aspecto discursivo. Las imágenes públicas que elaboraron de los grupos en contienda por el poder, la discusión pública sobre las características que debían tener los fundamentos del sistema político, y, en general, la participación en el debate público fueron una forma de hacer política, tan eficaz como las negociaciones directas, la formación de alianzas o la incidencia en los procesos electorales. Es decir, el debate público era un espacio de legitimación tan importante como las elecciones o las disposiciones constitucionales.

Sin embargo, esta parte de la actuación política yorkina no estuvo directamente relacionada con la estructura masónica, como sí, lo estuvieron las acciones que se analizan en el siguiente apartado.

\section{El rito de York como centro de acción política}

Para quienes se iniciaron en las "sociedades masónicas" que habían "levantado sus columnas ${ }^{21}$ bajo el rito de York", era claro que una de las principales finalidades de dichas sociedades era el sostén de las instituciones políticas, entendidas como el sistema republicano y federal ([“Apoteosis”], 1827). Esto implicaba que los yorkinos, no sólo como ciudadanos sino también como miembros del Rito, debían cuidar los fundamentos del edificio social, así como defender y respetar al gobierno de Guadalupe Victoria, que se había establecido sobre esas bases. Por tal razón, si algún miembro de una logia yorkina se manifestaba públicamente en contra del gobierno, o lo atacaba en los papeles públicos, era reprendido por los miembros de la Gran Logia Nacional Mexicana y conminado a desdecirse, como le sucedió a José María Alpuche cuando criticó las medidas tomadas por el gobierno en contra del marqués de Santángelo, un italiano que fue expulsado del país debido a sus publicaciones (Tornel, 1826a).

Otro de los principales deberes de los yorkinos era desprestigiar a los escoceses, difundiendo la negativa imagen pública que les habían creado, y tratar de mantenerlos lejos de los cargos públicos. Este deber era tan importante que, si no se cumplía con él y se sospechaba que un yorkino apoyaba a los escoceses, ya fuera de palabra o de obra, podía ser acusado de "infiel al rito de York" y ser sometido a un juicio masónico por ello, como le ocurrió al aprendiz Luis Zuloaga en Chihuahua (["Apoteosis"], 1827) y al propio José María Tornel en la ciudad de México (Secretaría, 1828).

Sus deberes como masones yorkinos también incluían trabajar para que los miembros de la organización yorkina, o al menos quienes compartían sus ideas políticas, resultaran triunfadores en los diversos procesos electorales, que iban desde las elecciones para los ayuntamientos hasta las de las legislaturas locales y el congreso nacional. Estos trabajos consistían principalmente en "formar la opinión" a favor de sus candidatos, pero también en cosas tan concretas como elaborar y repartir listas impresas con los nombres de los sujetos en quienes deseaban que recayeran los votos, apropiarse de las listas elaboradas por sus opositores para evitar que llegaran a las mesas electorales, o incluso cometer "irregularidades" en estos procesos, como votar en más de una ocasión ([“Apoteosis"], 1827).

Para 1828 los yorkinos ya habían logrado establecer logias por casi todo el territorio nacional, y habían consolidado su discurso legitimador, con lo cual la Gran Logia Nacional Mexicana estuvo en condiciones de desplegar todo su aparato organizativo, con miras a triunfar en los procesos electorales que tendrían lugar ese año, tanto para las legislaturas como para la presidencia de la república.

La dirigencia yorkina implementó un plan, perfectamente organizado, para ese fin. En junio de 1828 la Gran 
Logia Nacional Mexicana envió una plancha a todos los talleres de su jurisdicción para que comenzaran a formar la opinión a favor de los "patriotas" que debían ser nombrados diputados. Indicaba que dichos nombramientos debían recaer en individuos de probidad, ilustración, concepto público, conocida adhesión a la independencia y a las instituciones federales, e imponían como condición indispensable que pertenecieran al rito de York en opiniones y sentimientos. Los talleres debían ponerse de acuerdo mediante comisiones para formular su plan de operaciones (Gran Logia, 1828).

Por su parte, la Gran Logia formó en su seno una comisión de cinco individuos, con la que debían mantener correspondencia los talleres foráneos, para informarle sobre los individuos a los que se hubiera acordado nombrar diputados y acerca del estado que guardaba la opinión respecto a ellos, así como para mantenerla al tanto de cualquier dificultad que se presentara. Dicha comisión estaría encargada también de ponerse en contacto con los yorkinos que radicaran en los estados o territorios donde aún no se hubieran instalado logias del rito, a fin de que ellos dirigieran las elecciones conforme a las bases del plan que habían trazado (Gran Logia, 1828).

Pese a toda esta organización, el plan causó problemas, pues numerosos masones yorkinos deseaban ocupar los cargos públicos, lo cual ocasionó que algunos de los comisionados estatales se vieran precisados a solicitar a los dirigentes de la Gran Logia que les enviaran listas con los nombres de las personas que les parecían más apropiadas para presentarse a las elecciones (Costeloe, 1996: 174).

Sólo con este ejemplo, bastaría para comprender la forma en que la dirigencia yorkina utilizó la estructura jerárquica y organizativa de la masonería, sus lealtades y sus canales de comunicación, para realizar actividades de orden político. Sin embargo, esto fue aún más notorio en la contienda por la presidencia.

La elección del presidente tendría lugar en septiembre de 1828 y sería realizada por las legislaturas estatales, quienes debían nombrar, a mayoría absoluta de votos, dos individuos. Los votos provenientes de todos los estados serían contados por el Congreso Nacional. La persona que obtuviera más votos sería el presidente y el segundo lugar ocuparía la vicepresidencia de la República.

Los yorkinos analizaron cuidadosamente a qué candidato concederían su apoyo, pues había varios miembros de su agrupación que podían aspirar a la dirección del Ejecutivo. Entre ellos se encontraban Lorenzo de Zavala, Ignacio Esteva, José María Tornel, Anastasio Bustamante y Vicente Guerrero, a la sazón Gran Maestro de la Gran Logia Nacional Mexicana (Los amantes, 1828). ${ }^{22}$

La Gran Logia formó una comisión de cinco individuos para examinar las cualidades, virtudes y merecimientos de los distintos candidatos, la cual decidió otorgar su apoyo al "benemérito General Vicente Guerrero" (Herrera, 1828a). A partir de ese momento, los miembros de la Gran Logia emplearon los recursos que les ofrecía la organización nacional yorkina para buscar que Guerrero alcanzara el triunfo (Tornel, 1985: 311-312).

En primer lugar, los publicistas yorkinos realizaron una fuerte campaña en los papeles públicos, en la cual exaltaban las cualidades de Guerrero, y procuraban deslegitimar a su principal contrincante, Manuel Gómez Pedraza, sobre todo destacando que éste pertenecía a los escoceses, a quienes, como se recordará, los yorkinos calificaban de enemigos de la independencia, la república y la federación (Los Amantes, 1828; El Coyote, 1828; El Sol, 1828: 9 de agosto).

En segundo lugar, el Secretario de la Gran Logia, José Manuel Herrera, envió comunicados a las logias simbólicas locales, en las que les informaba que la comisión había elegido como candidato a la presidencia a Guerrero y para la vicepresidencia a Anastasio Bustamante. Les pedía que secundaran el plan, para lo cual sugería que los miembros de las logias en los estados incidieran en los ayuntamientos para que éstos expusieran que la opinión de los pueblos estaba decidida a favor de Guerrero (Herrera, 1828b). Todo parece indicar 
que esta solicitud de Herrera fue escuchada, pues en diversas partes del país los ayuntamientos enviaron representaciones a sus legislaturas solicitándoles que concedieran su voto a Guerrero, como hicieron las municipalidades de Orizaba y Veracruz (El Sol, 1828: 5 de octubre; Di Tella, 1994: 222).

A primera vista estas acciones podrían carecer de sentido, pues los votos los emitirían las legislaturas, y los ayuntamientos no tenían ninguna injerencia en las decisiones de éstas. Sin embargo, desde 1826 los publicistas yorkinos habían difundido una idea del sistema político en el que los ayuntamientos jugaban un papel fundamental, pues aunque carecían de representación política en sentido estricto, estaban formados por personajes que habían sido nombrados por elección popular, realizaban importantes trabajos en los procesos electorales, y podían hacer representaciones a nombre de sus pueblos, por lo cual poseían la fuerza suficiente como para considerar la expresión de su voz (Vázquez, 2008). Por tal razón, las representaciones a favor de Guerrero le otorgaban notable legitimidad a su candidatura, amén de que ponían gran presión sobre las legislaturas para que le otorgaran sus votos.

A pesar de ello, Guerrero no resultó electo como presidente; el triunfador fue Gómez Pedraza. Tras ese fracaso, los acontecimientos se precipitaron. Antonio López de Santa Anna encabezó un movimiento armado para colocar a Guerrero en la presidencia, y poco después hubo un motín en la Ciudad de México. Gómez Pedraza huyó de la ciudad y renunció a su triunfo. El congreso, al calificar las elecciones, dictaminó que las legislaturas habían votado en contra de los "deseos de sus comitentes", por lo que declaró insubsistente la elección y nombró presidente a Vicente Guerrero y vicepresidente a Anastasio Bustamante (Bocanegra, 1985: 505-509). Esta medida excedía las facultades que la Constitución había dado al Congreso, pero se explica si se considera que en la comisión encargada de calificar las elecciones había un considerable número de yorkinos, pues de trece legisladores que la componían, siete lo eran: Manuel García Tato, Vicente Güido de Güido, Ignacio Basadre, José María Bocanegra, José María Alpuche, José Sixto Berduzco y Juan Evangelista Guadalajara. $^{23}$

Algunos gobernadores interpretaron la llegada de Vicente Guerrero a la presidencia como una imposición del centro a la voluntad de los estados. Cuando Gómez Pedraza dejó la ciudad de México, se dirigió a Jalisco, en donde pensaba que iniciaría la defensa de su gobierno. Por su parte, los generales Vicente Filisola, quien había sido yorkino pero ahora se oponía al movimiento a favor de Guerrero, y Melchor Múzquiz, que había sido gobernador del estado de México y era enemigo de Lorenzo de Zavala, se habían reunido en Puebla para marchar en contra de Guerrero, pero la milicia local se amotinó. Una cosa semejante pasó en Guanajuato. El gobernador Carlos Montes de Oca buscó establecer una alianza con Jalisco, Michoacán, San Luis Potosí y Zacatecas, pero los milicianos bajo el mando de Luis Cortázar se pronunciaron a favor del antiguo caudillo insurgente. La documentación existente en el Archivo General de la Nación muestra que Guerrero estaba en comunicación con oficiales de mediana y baja graduación en las milicias y en el ejército, en especial en las unidades que contaban con talleres ambulantes (Ávila, 2004b: t. I, p. 85).

Con este resultado final puede verse que, aunque el plan implementado por la Gran Logia no haya sido suficiente para que Guerrero fuera designado presidente, las acciones que habían realizado sí les fueron muy útiles, pues gracias a las representaciones de los ayuntamientos, al discurso yorkino en los papeles públicos y a los movimientos armados y populares a favor de Guerrero, los yorkinos pudieron sostener - en el congreso y en los impresos- que los representantes no habían respetado los deseos de sus comitentes, lo cual les parecía motivo suficiente para descalificar la elección de Gómez Pedraza. Con ese argumento ignoraron los votos de las legislaturas y pretendieron dar legitimidad a la llegada de Guerrero a la presidencia, aunque ésta no haya sido por las vías constitucionales. 
Sin embargo, el triunfo no les duró mucho. Durante los pocos meses de 1829 que Guerrero estuvo al frente del Ejecutivo tuvo que afrontar numerosos problemas, desde el intento de reconquista española encabezado por Isidro Barradas hasta la escasez del erario y las quejas por las medidas impositivas que trataba de establecer su Ministro de Hacienda, Lorenzo de Zavala (Serrano Ortega, 2002: 87-110). Además, hubo una escisión en las filas yorkinas, que por una parte parece haberse debido a que los sectores exaltados de las obediencias yorkinas estaban descontentos con la política conciliadora de Guerrero con los miembros de otros grupos políticos; y por otra, al temor que despertaba en algunos yorkinos y en muchos otros actores políticos la movilización popular a la que Guerrero y los suyos habían recurrido (Vázquez, 2008).

Todo este proceso culminó a finales de 1829 con un pronunciamiento para derrocar al presidente, encabezado por el propio Anastasio Bustamante, quien fungía como vicepresidente y había sido un connotado miembro de la organización yorkina. En él recayó la titularidad del Ejecutivo cuando se derrotó al gobierno de Guerrero.

Con dicho pronunciamiento, conocido como el Plan de Jalapa, llegó al poder un grupo que deseaba reducir las vías de participación política que se habían abierto durante los años anteriores y que procuraba aplicar un liberalismo moderado (Serrano y Chust, 2008), pero también necesitaba impedir que sus contrincantes intentaran recuperar el control de los negocios públicos, para lo cual, entre otras cosas, era preciso desarticular a los yorkinos.

Durante 1830 el gobierno emanado del Plan de Jalapa encarceló o formó causas a reconocidos escritores yorkinos, como Pablo de Villavicencio, Luis Espino y José Ramón García Ugarte (Suárez y Navarro, 1987: 203-204; Bustamante, 2000). Lucas Alamán, quien era el ministro de Relaciones, comenzó a destituir a las autoridades yorkinas que se habían establecido el año anterior. Como desde 1828 se había dictado una ley de prohibición de sociedades secretas, hubo numerosas delaciones de logias estatales y de su relación con las legislaturas, los ayuntamientos o los gobernadores, de modo que la pertenencia a las obediencias del rito de York se convirtió en una causa para perder el cargo ([Ayuntamiento], 1830; Videgaray, 1830; Costeloe, 1996: 257). A pesar de ello algunas logias locales, como la de Zacatlán, siguieron trabajando, pero fueron objeto de persecución, tanto por las autoridades civiles como las eclesiásticas (Autos, 1830).

Finalmente, el gobierno comenzó un claro proceso de desarticulación de lo que quedaba de la plana mayor yorkina. Alpuche fue acusado de conspiración por haber invitado a Manuel Mier y Terán a iniciar una revuelta contra el gobierno y se le expatrió por seis años. Anastasio y Mariano Zerecero, así como Lucas Balderas, también se vieron envueltos en una conspiración; Anastasio fue expatriado por cinco años y Mariano condenado a la pena capital, aunque recibió el indulto, al parecer gracias a la intervención de Anastasio Bustamante. Balderas fue arrestado, igual que Manuel Reyes Veramendi. Finalmente a Isidro Gondra se le acusó de conspiración y de contribuir con Guerrero al desarrollo de la guerra contra el gobierno que estaba dirigiendo en el Sur, por lo que se le desterró por cuatro años. Hubo también numerosas acusaciones en contra de Zavala, y aunque no prosperaron, él decidió salir del país rumbo a Estados Unidos. A su lado partieron otros dos importantes publicistas yorkinos, editores del Correo de la Federación: Ramón Ceruti y el llamado conde Cornaro. Juan Nepomuceno Almonte, huyó y permaneció oculto cuando estuvo cerca de verse implicado en un problema por recibir una correspondencia secreta de la que tuvo noticia el gobierno. Además, el senador Hernández Chico, redactor del periódico de oposición El Atleta, murió el 1 de abril de 1830. De ese modo, la dirigencia yorkina quedó prácticamente destruida (AGSCJN, AP; Registro, 1830: 10 de marzo y 10 de septiembre; Ibar, 1830: 21 de mayo; Costeloe, 1996:265-271; Bustamante, 2000).

Es posible entonces sostener que, a causa de las divisiones internas, de los conflictos que hubo de afrontar la plana mayor yorkina cuando llegó al poder durante la presidencia de Guerrero, y de la persecución de que 
fueron objeto los yorkinos durante la administración Alamán, ${ }^{24}$ a partir de 1830 las obediencias del rito de York dejaron de funcionar como centro de acción política. A pesar de ello, no desaparecieron las lealtades que éstas generaban, pues durante el desarrollo de la Guerra del Sur, Vicente Guerrero buscó el apoyo de diversos yorkinos, apelando a su condición de hermanos, y al discurso antiescocés, como se observa en la carta que dirigió a Francisco Santa María, en la que sostenía que el peligro en que se encontraban las instituciones federales lo había decidido a tomar las armas, pues aseguraba que todo el Plan de Jalapa había sido fraguado en el Gran Consistorio Escocés, y que éste dirigía las acciones de los generales Nicolás Bravo y Gabriel Armijo (AGN, Hist.). Así, pese a su desprestigio, la masonería siguió siendo considerada, durante un tiempo, como una herramienta eficaz para la acción política, pues apenas cuatro años después se fundó el nuevo grupo de los Yorkinos Federalistas, también con miras claramente políticas (Lafragua, s/f).

\section{Consideraciones finales}

Gracias a su labor discursiva y al aparato organizativo que implementaron mediante la estructura masónica e institucional, durante algunos años los yorkinos lograron constituirse en una importante fuerza política, que tuvo injerencia casi a nivel nacional. Los actores políticos yorkinos que se encontraban en la capital tuvieron la posibilidad de coordinar su accionar político con el de sus partidarios en los estados, en buena parte gracias a la diseminación de logias, a su estructura jerárquica y a los canales de comunicación de la masonería. La pertenencia a los cuerpos del rito de York fue un medio al que recurrieron los dirigentes del mismo para tratar de unificar las voluntades y los esfuerzos de sus miembros hacia la consecución de ciertos fines políticos, como los triunfos electorales. De ese modo, los yorkinos lograron la acción política concertada de una buena parte de la clase política de todo el país.
Es claro que, como ha señalado Marco Flores, el que un masón reciba indicaciones de los grados superiores no implica que necesariamente las cumpla, de modo que es preciso no dar por hecho que los yorkinos actuaron siempre de manera conjunta y conciliada (Flores, 2005). Lo interesante es observar cómo la estructura masónica proporcionó a los grupos políticos de una nación recién constituida espacios y herramientas para tratar de vincular a los actores políticos de distintas partes del país, para darles a conocer sus planes, principios y proyectos políticos, para obtener su apoyo e incluso para tener injerencia en la política local. La estructura masónica le resultó muy útil, durante un tiempo, a algunos grupos políticos mexicanos. Que el resultado final no haya sido el que los dirigentes yorkinos deseaban resulta secundario, porque lo que sí sucedió fue que al menos un sector de la población políticamente activa del país empezó a actuar de manera conjunta y coordinada, y eso contribuyó a la formación de una clase política nacional.

\section{Notas}

${ }^{1}$ De acuerdo con la definición de Héctor Calderón (1999), se entiende por masonería una "fraternidad secreta, libre, jerárquica y selectiva, de extensión internacional y estructura federal, que tiene una tradición racional y humanista, siendo su principal actividad el estudio filosófico de la conducta humana, de la ciencia y de las artes, y que ejemplifica sus enseñanzas con símbolos y alegorías tradicionales, tomadas del arte real de la construcción, que se explican gradualmente para orientar a sus miembros hacia la práctica de las virtudes y hacia su evolución personal y colectiva". Partiendo de esa base, se asume que la masonería, como institución, no tiende necesariamente a la acción política. Sin embargo, como mostraré en este trabajo, la organización yorkina en México, durante la primera década de vida independiente del país, sí la tuvo.

${ }^{2}$ Una obediencia masónica es una federación de logias jurisdiccionadas a una misma autoridad. Las logias son 
pequeños grupos o asambleas, debidamente organizados, en que se reúnen los masones. También se llama así al lugar donde realizan dichas asambleas. El rito es el conjunto de reglas y preceptos en función de los cuales se realizan las ceremonias e instrucciones secretas de los grados; también se emplea ese nombre al gobierno masónico, es decir, a los altos cuerpos que dirigen y administran la masonería. Los grados son los niveles jerárquicos que van alcanzando los masones conforme van avanzando en las iniciaciones que enseñan la doctrina y los fines de la orden. El número de grados, y sus denominaciones, varían según el rito. Los tres primeros se llaman simbólicos y son reconocidos por todos los ritos; los subsecuentes se conocen como capitulares, filosóficos y administrativos. La iniciación es la serie de ceremonias que se realizan para el ingreso a la orden y la ascensión en los grados.

${ }^{3}$ Nombre simbólico que se otorga a los documentos masónicos, en especial de las actas de los trabajos de las logias.

${ }^{4}$ En el caso de la presente investigación, los documentos encontrados me han permitido confirmar las filiaciones masónicas de algunos de los personajes de que se habla en el trabajo; Michael Costeloe (1996) pudo corroborar la pertenencia a logias del rito de York de otros de ellos; para los restantes, se ha valorado la información contenida en los papeles públicos y se ha considerado válida cuando el cruce de la información parece suficiente para ello.

${ }^{5}$ Varios historiadores hacen referencia a esta pionera logia escocesa, aunque difieren en su ubicación.

${ }^{6}$ Cuerpo creado en el rito escocés con los Grandes Inspectores de la orden, los Presidentes de los Consejos de Sublimes Príncipes y 25 de los Sublimes Príncipes de más edad en el grado.

${ }^{7}$ Capítulo es el nombre que reciben los talleres de los grados superiores al simbolismo.

${ }^{8}$ Gran consejo es la denominación genérica de ciertas cámaras de los altos grados.

${ }^{9}$ Estos personajes se incorporaron a la logia Caballeros Racionales, o Sociedad de Americanos, que en sentido estricto no pertenecía a la masonería, sino que adoptó sus formas con la intención de establecer una organización para los americanos que buscaban la independencia. Sin embargo, esta vinculación les permitió conocer los mecanismos de organización masónica y su posible utilidad como espacio de acción política. Es posible que por ello Fagoaga y Santa María se hayan incorporado más tarde a las logias establecidas en México.

${ }^{10} \mathrm{El}$ caso mejor estudiado es, sin duda, el de la Península de Yucatán que ha revisado Campos.

${ }^{11}$ Debo esta referencia a la generosidad de Ruth Solís Vicarte, quien me hizo el favor de proporcionarme este importante documento.

${ }^{12}$ Carta patente es la carta o concesión de una Gran Logia a favor de un taller masónico, para que pueda constituirse y trabajar de forma regular. Gran Logia es el cuerpo superior al que está incorporado un grupo de logias. ${ }^{13}$ Se denomina logias simbólicas a las que trabajan en los tres primeros grados: aprendiz, compañero y maestro.

${ }^{14}$ Taller es otro nombre con que se denomina a la logia. Los talleres ambulantes, como su nombre lo indica, son aquellos que no tienen un sitio fijo de reunión; solían instaurarse entre los miembros de algún cuerpo del ejército. ${ }^{15}$ Cuerpo del rito de York, formado por los masones que habían alcanzado los grados del Real Arco, cuatro grados superiores del rito.

${ }^{16}$ El grado de Vicente Guerrero como Gran Maestro de la Gran Logia Nacional Mexicana puede constatarse en: Secretaría, 1828.

${ }^{17}$ La plancha en la que se habla de la existencia de esta Gran Logia fue publicada en un periódico antiyorkino, lo cual podría hacer dudar de su autenticidad; sin embargo, ésta puede constatarse mediante una carta enviada por Juan Rodríguez a Anastasio Zerecero en la que se hace referencia a la plancha en cuestión (Costeloe, 1996: 174).

${ }^{18}$ No se han podido localizar documentos que comprueben la filiación de Nicolás Bravo al rito escocés, pero en el Correo de la Federación Mexicana (1828, 9 de febrero) se le señaló como Gran Maestro de dicho rito. Cabe señalar que hasta el momento no se ha encontrado ninguna respuesta de Bravo negando tal grado y filiación, práctica 
que era común en la época cuando se deseaba desmentir las afirmaciones que aparecían en los papeles públicos.

${ }^{19}$ Como ejemplos de este discurso ver, entre varios más incluidos en la bibliografía, Diálogo, 1826; Simón el trompetero, 1826; Hoy truenan, 1826; Dávila, 1827; L. M. Federación, 1827; Llegada; 1827.

${ }^{20}$ Un ejemplo de ello es la descripción que las publicaciones de orientación yorkina hicieron del Plan de Montaño, que fue un movimiento dirigido por Nicolás Bravo en contra de las sociedades secretas y de la influencia que Poinsett tenía en el gobierno mexicano. Ver Correo de la Federación Mexicana (1828, 1 de enero) y El Amigo del Pueblo (1828, 2 de enero).

${ }^{21}$ Término con el que se designa la constitución formal de una logia y el comienzo de sus trabajos masónicos.

${ }^{22}$ Carlos María de Bustamante señala en su diario (30 de julio de 1828) que el autor del folleto en que se basa esta referencia fue José Manuel Herrera, secretario de la Gran Logia.

${ }^{23}$ Los nombres de los diputados se tomaron de Costeloe (1996) y Bocanegra (1985) y fueron cotejados con las listas de Ibar (1830), Mateos (2003), los documentos de los Catálogos de la Casa de Subastas Louis C. Morton y la circular de la Secretaría de la Gran Logia Nacional Mexicana (1828).

${ }^{24}$ Así se le llamaba al gobierno de Anastasio Bustamante, pues muchos consideraban que era Lucas Alamán quien realmente dirigía las acciones de las diversas autoridades.

\section{Fuentes de archivo}

Archivo General de la Nación (AGN), fondo Inquisición, vol. 1461, exp. 4, fs. 129-131 y vol. 1463, exp. 9, fs. 97-99.

Archivo General de la Nación (AGN), fondo Indiferente de guerra, vol. 22, fs. 27-30.

Archivo General de la Nación (AGN), fondo Historia, vol. 587, exp. s/n, fs. 45-46r.

Archivo de la Suprema Corte de Justicia de la Nación (ASCJN), Asuntos penales siglo XIX, exp. 83.
Autos formados sobre la conducta del Presbitero Antonio Arroyo, ministro de Santiago Chignahuapan, por pertenecer a la logia yorkina (1830), Puebla. Archivo Histórico del Arzobispado de México, fondo Episcopal, Sección Provisorato, Serie Autos contra eclesiásticos, Caja 24, exp. 14, 118 fs.

\section{Hemerografía}

Correo de la Federación Mexicana (1828), 1 de enero, núm. 426, México.

Correo de la Federación Mexicana (1828), 9 de febrero, núm. 465, p. 4.

Chavero, José María (1829), "Comunicado", en Correo de la Federación Mexicana, 26 de agosto, núm. 449, México.

El Amigo del Pueblo (1828), 2 de enero, núm. 1, México.

El Amigo del Pueblo (1828), 23 de enero, núm. 4, México.

El Patriota (1827), 25 de abril, núm. 1, Puebla.

El Patriota (1827), 4 de julio, núm. 11, Puebla.

El Patriota (1827) 13 de julio, núm. 13, Puebla.

El Sol (1828), 9 de agosto, núm. 1884, México.

El Sol (1828), 5 de octubre, núm. 1939, México.

[Gran Consistorio de Yucatán] (1822), "Discurso masónico pronunciado al abatimiento de columnas del gran consistorio de Yucatán al separarse del de la Havana y reunirse al gran consejo de Veracruz", en La inquisición se pone o la religión se acaba, núm. 2, México, pp. 3-6.

Gran Logia Nacional Mexicana (1828), "[Plancha circulada por la Gran Logia Nacional Mexicana], en Águila Mexicana, 17 de septiembre, año IV, núm. 261, México.

Ibar, Francisco (1830), Regeneración política de la República Mexicana, Imprenta a cargo del ciudadano Tomás Uribe y Alcalde, México.

Registro Oficial del Gobierno de los Estados Unidos Mexicanos (1830), 10 de marzo, núm. 49.

Registro Oficial del Gobierno de los Estados Unidos Mexicanos (1830), 10 de septiembre, núm. 138.

[Tornel], José María (1826a), [“Carta dirigida a don José D”], en El Sol, 31 de julio, núm. 1143, México. 


\section{Manuscritos e impresos}

["Apoteosis de Hidalgo"] (1827), T $\therefore$ número 543, Criminal seguida contra el ex-h. Luis Zuluaga, AprendizM $\therefore$, por infiel al rito de $Y \therefore$, Chihuahua.

Arista Mariano (1826), [Carta al Muy Excelente Capítulo de Arcos Reales La Libertad], Oriente de México, a los 3 días del $6^{\circ} \mathrm{m} \therefore \mathrm{m} \therefore \mathrm{a} \therefore 1 \therefore 5826$.

["Aurora Yucateca"] (1823), [Carta de la logia "Aurora Yucateca" a Melchor Álvarez], ler día del ler $\mathrm{m} \therefore \mathrm{m} \therefore \mathrm{a} \therefore \mathrm{d} \therefore \mathrm{l} \therefore \mathrm{v} \therefore 1 \therefore 5823$.

[Ayuntamiento de Toluca] (1830), Representación que el ayuntamiento y vecindario de la ciudad de Toluca ha dirigido a la Cámara de Senadores, pidiendo se declare nula la legislatura del Estado de México, México.

Bustamante, Anastasio (1826), [Carta, no se indica destinatario], 3 de julio.

Dávila, Rafael (1827), Taller de cohetería. Diálogos crítico-alegóricos entre un cohetero y un tamborilero, México.

Diálogo entre un liberal moderado y un exaltado sobre los empleos (1826), Guadalajara.

El costeño de Acapulco (1827), La ejecución de justicia contra el coronel Mangoy, la causa son los coyotes porque intentó su expulsión, México.

El coyote manso (1828), Manuel GómezPedraza, segundo emperador de los mexicanos, México.

Gómez Pedraza, Manuel (1830), Manifiesto que Manuel GómezPedraza, ciudadano de la Repúblicade Méjico, dedica a sus compatriotas; o sea una reseña de suvida pública, Nueva Orleáns, reimpreso en Guadalajara en la Oficina de Brambilas, 1831, p. 29.

Guerrero, Vicente (1827), [Poder otorgado a Santiago Abreu], 3 de mayo.

Herrera, José Manuel (1826), [Carta dirigida a José Teurbe Tolón], 27 de octubre, México.

Herrera, José Manuel (1828a), [Plancha dirigida a la M $\therefore$ R $\therefore$ L $\therefore$ núm. 54, Apoteosis de Hidalgo], México, a los 28 días del $4^{\circ}$ mes de 5828 .

Herrera, José Manuel (1828b), [Carta dirigida a la R $\therefore$ L $\therefore$ Apoteosis de Hidalgo], México, a los 13 días del $6^{\circ}$ $\mathrm{m} \therefore \mathrm{m} \therefore \mathrm{a} \therefore 1 \therefore 5828$.
Hoy truenan losescoceses como Judas en la Gloria (1826), México. Lafragua, José María, [Apuntes sobre su vida pública hasta 1841], s/l, s/f, Colección Lafragua.

L. M. Federación (1827), Lista de los escoceses y apunte de sus maldades, Puebla.

Los amantes del bien público (1828), Oigan todos los congresos el voto de la República, o sea, la expresión de la voluntad general, con respecto a los patriotas en quienes deben recaer los altos empleos de presidente y vicepresidente, México.

Llegada de D. Francisco de Paula a Veracruz (1827), Puebla.

Secretaría de la M $\therefore$ R $\therefore$ G $\therefore$ L $\therefore$ N $\therefore$ M $\therefore$ (1828), [Circular núm. 25 de la Gran Logia Nacional Mexicana sobre el impreso titulado Gracias singulares del ciudadano José María Tornel, dictaminando que no ha lugar a formación de causa contra Tornel], $\mathrm{O} \therefore$ de México a los 4 días de $5 \therefore \mathrm{m} \therefore \mathrm{m} \therefore$ a $\therefore 1 \therefore 5828$.

Simón el Trompetero (1826), Quedaron los escoceses como el que chifló en la loma, México.

Tornel, José María (1826b), [Carta dirigida A $\therefore$ M $\therefore$ E $\therefore$ C $\therefore$ D $\therefore \mathrm{R} \therefore \mathrm{A} \therefore \mathrm{N} 1$ tit. Libertad], Or $\therefore$ de Méjico a $\operatorname{los} 28 \mathrm{~d} \therefore$ del $5^{\mathrm{o}} \mathrm{m} \therefore \mathrm{m} \therefore \mathrm{a} \therefore 1 \therefore 5.826$.

Videgaray, Andrés (1830), Almoneda de las joyas, instrumentos y muebles mazónicos, que por fallecimiento del Rito Yorkino venden sus albaceas para cubrir a sus infinitos acreedores, Puebla.

Yadspat (1827), Contestación a un valiente retador, Victoria de Durango.

Zavala, Lorenzo de (1826), 2 de abril, Comunicado de la $\mathrm{A}$ : $\mathrm{R} \therefore \mathrm{G} \therefore \mathrm{L} \therefore \mathrm{N} \therefore \mathrm{M} \therefore$ al M $\therefore$ E $\therefore$ Capítulo $\mathrm{N}^{\circ} \mathrm{I}$ con el distintivo de la Libertad.

\section{Bibliografía}

Alamán, Lucas (1986), Historia de Méjico desde los primeros movimientos que prepararon su independencia en el año de 1808 hasta la época presente, tomo V, México: Libros del Bachiller Sansón Carrasco.

Ávila, Alfredo (2004a), Para la libertad. Los republicanos en tiempos del imperio 1821-1823, México: Universidad Nacional Autónoma de México. 
Ávila, Alfredo (2004b), "La presidencia de Vicente Guerrero", en Will Foler, Presidentes mexicanos, México: INEHRM.

Ávila, Alfredo (2004c), "El partido popular en México", en Historia y Política, núm. 11, pp. 35-63.

Bocanegra, José María (1985), Memorias para la historia de México independiente, tomo I, México: INEHRM

Bustamante, Carlos María de (2000), Diario histórico de Carlos María de Bustamante, edición de Josefina Zoraida Vázquez y Héctor Cuauhtémoc Hernández Silva, México: CIESAS/El Colegio de México, CD-1.

Calderón, Héctor M. (1999), Definición de la Francmasonería Moderna y descripción de sus linderos, México: Herbasa.

Campos García, Melchor (2003), Sociabilidades políticas en Yucatán. Un estudio sobre los espacios públicos, 1780-1834, Mérida: Universidad Autónoma de Yucatán/Consejo Nacional de Ciencia y Tecnología.

Castellano Gil, José Manuel (1996), La masonería española en Cuba, Ayuntamiento de La Laguna/Cabildo de Tenerife/CEHME/Centro de la Cultura Popular Canaria, La Laguna.

Costeloe, Michael (1996), La primera república federal de México (1824-1835). Un estudio de los partidos politicos en el México independiente, México: F.C.E.

Di Tella, Torcuato (1994), Política nacional y popular en México, 1820-1847, México: F.C.E.

Flores Zavala, Marco Antonio (2005), "La masonería en la República federal. Apuntes sobre las logias mexicanas (1821-1840)", en Miño Grijalva, Manuel, Terán Fuentes, Mariana, et al (coords.), Raíces del federalismo mexicano, Zacatecas: Universidad Autónoma de Zacatecas/Secretaría de Educación y Cultura del Gobierno del Estado de Zacatecas, pp. 125-136.

Frau Abrines, Lorenzo (1998), Diccionario enciclopédico abreviado de la masonería, México: Herbasa.

Mora, José María Luis (1963), Obras sueltas, México: Porrúa.

Madero Quiroga, Adalberto Arturo (comp.) (2002), Ensayos de David Alberto Cossío, Monterrey: Cámara de Senadores.
Mateos, José María (2003), Historia de la masonería en México, México: Herbasa.

Rich, Paul y Guillermo De los Reyes (1997), “Towards a Revisionist View of Poinsett: Problems in the Historiography of Mexican Freemasonry", en Part II. 〈www.paulrich.net/home/papers.php〉 [1l de octubre de 2009].

Rojas, Rafael (2003), La escritura de la independencia. El surgimiento de la opinión pública en México, México: Taurus/ CIDE.

Serrano Ortega, José Antonio (2002), "Tensar hasta romperse, la política de Lorenzo de Zavala", en Ludlow, Leonor (coord.), Los Secretarios de Hacienda y sus proyectos (1821-1933), México: UNAM, pp. 87-110.

Serrano, José Antonio y Chust, Manuel (2008), “Adiós a Cádiz: el liberalismo, el doceañismo y la revolución en México, 1828-1835", en Rodríguez O., Jaime E. (coord.), Las nuevas naciones. España y México 1800-1850, Madrid: Mapfre, pp. 191-225.

Solís Vicarte, Ruth (1997), Las sociedades secretas en el primer gobierno republicano (1824-1828), México: ASBE.

Suárez y Navarro, Juan (1987), Historia de México y del general Antonio López de Santa Anna, México: INEHRM.

Tornel, José María (1985), Breve reseña histórica de los acontecimientos más notables de la nación mexicana, México: INRHRM.

Vázquez Semadeni, María Eugenia (2008), La interacción entre el debate público sobre la masonería y la cultura política, 1761-1830, Tesis de doctorado, Zamora: El Colegio de Michoacán.

Zavala, Lorenzo de (1831-1832), Ensayo histórico de las revoluciones de México, desde 1808 hasta 1830, F. Dupont et G. Laguionis.

Zuleta, María Cecilia (2003), "Raíces y razones del federalismo peninsular, 1821-1825”, en Vázquez, Josefina Zoraida (coord.), El establecimiento del federalismo en México (1821-1827), México: El Colegio de México, pp. $155-188$. 